\title{
Post-intervention effects on screen behaviours and mediating effect of parental regulation: the HEalth In Adolescents study - a multi-component school-based randomized controlled trial
}

Ingunn H Bergh ${ }^{1 *}$, Maartje M van Stralen ${ }^{2,5}$, Mona Bjelland ${ }^{3}$, May Grydeland ${ }^{3,4}$, Nanna Lien ${ }^{3}$, Knut-Inge Klepp ${ }^{3}$, Sigmund A Anderssen ${ }^{4}$ and Yngvar Ommundsen ${ }^{1}$

\begin{abstract}
Background: To improve effectiveness of future screen behaviour interventions, one needs to know whether an intervention works via the proposed mediating mechanisms and whether the intervention is equally effective among subgroups. Parental regulation is identified as a consistent correlate of screen behaviours, but prospective evidence as well as the mediation role of parental regulation is largely lacking. This study investigated postintervention main effects on screen behaviours in the HEIA-intervention - a Norwegian school-based multiplebehaviour study, as well as mediation effects of parental regulation by adolescents' and parents' report. In addition, moderating effects of gender and weight status on the intervention and mediating effects were explored.

Methods: Participating schools were randomized to control $(n=25)$ or intervention $(n=12)$ condition. Adolescents ( $n=908$ Control; 510 Intervention) self-reported their weekday and weekend TV-viewing and computer/game-use. Change in adolescents' behaviours was targeted through school and parents. Adolescents, mothers $(n=591$ Control; 244 Interventions) and fathers ( $n=469$ Control; 199 Intervention) reported parental regulation of the screen behaviours post-intervention (at 20 month). The product-of-coefficient test using linear regression analysis was conducted to examine main and mediating effects.

Results: There was no intervention effect on the screen behaviours in the total sample. Gender moderated effect on weekend computer/game-use, while weight status moderated the effect on weekday TV-viewing and computer/game-use. Stratified analyses showed a small favourable intervention effect on weekday TV-viewing among the normal weight. Parental regulation did not mediate change in the screen behaviours. However, stronger parental regulation was associated with less TV-viewing and computer/game-use with effects being conditional on adolescents' versus parental reports. Parental regulation of the screen behaviours, primarily by the parental report, was associated with change in the respective behaviours.

Conclusion: Multiple behaviour intervention may not affect all equally well, and the effect may differ by weight status and gender. In future interventions parents should be encouraged to regulate their adolescents' TV-viewing and computer/game-use on both weekdays and weekends as parental regulation was identified as a determinant of these screen behaviours. However, future intervention studies may need to search for more effective intervention strategies targeting parental regulation.
\end{abstract}

Trial registration: Current Controlled Trials ISRCTN98552879

Keywords: Sedentary behaviour, Obesity prevention, Intervention, Mediation, Moderation, Adolescents

\footnotetext{
* Correspondence: ingunn.holden.bergh@nih.no

1 Department of Coaching and Psychology, Norwegian School of Sport

Sciences, PB 4014 Ullevaal Stadion, Oslo NO-0886, Norway

Full list of author information is available at the end of the article
} 


\section{Background}

Overweight and obesity among children and adolescents are associated with adverse physical and psychosocial health consequences $[1,2]$. The high prevalence rates of both overweight/obesity and the unhealthy energybalance related risk behaviour (diet, physical activity and sedentary behaviours) among young European adolescents calls for effective interventions [3]. Interventions targeting diet and physical activity have shown positive effects on BMI in children and adolescents [4], and a recent meta-analysis show that reducing time spent on screen behaviours as a part of multiple behaviour interventions can affect BMI in young people [5].

Overall sedentary time, as well as time spent in front of electronic screens such as TV and computers are associated with other unhealthy behaviours (e.g. snacking, smoking and alcohol use), poorer socio-cognitive development, unfavourable psychological and physical health outcomes, including higher body fatness in youth [6-10]. Adolescents engage in a variety of sedentary pursuits, but TV-viewing and computer-use (e.g. playing games, surfing on the internet, social media-use) contribute to a major portion of the time young people spend being sedentary [11,12]. In addition, screen behaviours are established quite early in life, and seem relatively stable over time [13,14].

Interventions to reduce screen behaviours have primarily focused on TV-viewing and have to a great extent been implemented as part of multiple behaviours interventions $[9,15]$. Meta-analyses show that interventions to reduce screen time can be effective, but effects are small $[16,17]$. The effect of recent multiple behaviour interventions on TV-viewing are however mixed, with some studies showing an effect [18], some revealing an unexpected effect [19] or studies showing an effect among subgroups only [20,21].

Behaviours can be changed by interventions targeting modifiable factors associated with the behaviours, the so called mediators [22]. Knowledge about how to optimise effects of interventions targeting screen behaviour has been called for [16], but to improve effectiveness one needs to know whether an intervention works via the proposed mechanisms, by conducting mediation analysis [23].

Up till now most studies exploring mediators of intervention effects have focused on personal mediators [24]. Emerging evidence, however, shows that health behaviours in youth are highly influenced by environmental factors, and home environmental factors in particular [24]. Parental rules and regulation on screen time have been identified as one of few consistent modifiable correlates of children's and adolescents' screen behaviours [25-30], but prospective evidence of determinants of screen time behaviours is lacking [31]. Also, just a couple of studies have examined potential mediators of screen behaviour change, and none have to our knowledge investigated mediated effects of home environmental variables factors like parental regulation on changes in screen behaviours [24]. Furthermore, differences in associations of parents' and adolescents' report of regulation with adolescents' TV-viewing and computer usage have been found [26], and investigation of both adolescents' and parents' report of screen behaviour regulation is warranted [32].

In addition, one type of intervention may not affect all equally well, and intervention effects and their mediators may not be equally effective across subgroups [33]. In the HEIA-study - a multi-component school-based obesity prevention intervention, we have previously reported mid-way effects (after eight months) on screen behaviours in girls but not in boys, while weight status moderated effect on computer/game-use among boys [34]. Hence, by examining whether intervention effects on screen behaviours are moderated by gender and weight status and whether gender and weight status moderate the mediators, it is possible to identify for whom an intervention is most (in)effective, as well as whether mechanisms of change differ by these subgroups.

The aims of the present study were: 1) to examine the effects of HEIA intervention on screen behaviours (TV/ DVD-viewing and computer/game-use) post-intervention; 2) to assess whether parental regulation of TV-viewing and computer/game-use (as perceived by the adolescents and reported by mother and fathers) mediated intervention effects on screen behaviours and 3) to explore whether gender and weight status moderated the intervention and mediated effects.

\section{Methods}

The HEIA study was a Norwegian 20 month randomized controlled school-based trial among 11-13 year-olds. A healthy weight development was promoted through targeting changes in physical activity, screen- and dietary behaviours. This paper focuses on screen behaviours only. The intervention intervened on determinants framed within a social-ecological approach as described in the conceptual model of the HEIA-study. A detailed description of the design and the development of the study is presented previously [35].

Ethical approval and research clearance was obtained from the Regional Committees for Medical Research Ethics and the Norwegian Social Science Data Service.

\section{Procedure and participants}

Schools were recruited from town/municipalities in seven counties in the south-eastern part of Norway. For logistic reasons schools had to have at least 40 pupils enrolled in $6^{\text {th }}$ grade. Thirty seven schools out of 177 eligible schools accepted the invitation, and 12 schools 
were randomly assigned by simple drawing to the intervention group and 25 to the control group (Figure 1). All the $6^{\text {th }}$ graders in these schools $(n=2165)$ and their parents/legal guardians (hereafter called parents) were invited to participate. Of these, 1580 returned a signed, parental informed consent form for the adolescents.

Baseline data were collected during four weeks in September 2007 in $6^{\text {th }}$ grade and post-intervention data at the end of $7^{\text {th }}$ grade in May 2009. Adolescents $(n=$ 1418: 908 Control; 510 Intervention) and their parents, both mothers $(n=835)$ and fathers $(n=668)$ who participated at both baseline and post-intervention are included in the analyses (Figure 1).

\section{Intervention}

A 20 month multi-component intervention targeting energy-balance related behaviours was implemented in the two last years of primary school. It consisted of individual-, group-, and environmental strategies to promote a healthy development in the participants' dietary, physical activity and screen time behaviours during school hours and in leisure time. The intervention was hypothesized to have a synergistic effect on the targeted behaviours, and is described in detail elsewhere [35,36].

The team of teachers at the involved grade levels led the implementation. Principals, school- and parent committees, and health nurses were also involved and informed about the intervention. The implementation was initiated by a yearly kick-off meeting with the teachers to ensure they knew the rationale and were familiar with the various intervention components. Throughout the school year the teachers received external support in the form of short monthly e-mail from the HEIA-study group to remind them about what parts of the intervention to implement.

The $6^{\text {th }}$ grade intervention targeted primarily the pupils' diet and physical activity. In $7^{\text {th }}$ grade a computertailoring program was added to the intervention. The program included one session specifically targeting screen behaviours (plus one session targeting physical activity and two sessions targeting dietary behaviours). It was implemented during school hours and each session took about 15 minutes to complete. After completing the screen behaviour session in which the adolescents answered questions about their own screen behaviours (Additional file 1), each adolescent received a personal tailored feedback letter with specific suggestions on what (or not) and how to change their own TV-viewing and computer/game-use. In addition, two out of eight parental fact sheets implemented in $7^{\text {th }}$ grade included focus on screen behaviours. The first of these facts sheets informed parents about the targeted behaviours of the intervention in $7^{\text {th }}$ grade (including screen behaviours) and encouraged parental involvement. The theme for the other fact sheet was: "TV-viewing - the most common leisure time activity among Norwegian children/adolescents". The specific targeted determinant in this fact sheet was parental regulation of TV-viewing and computer/

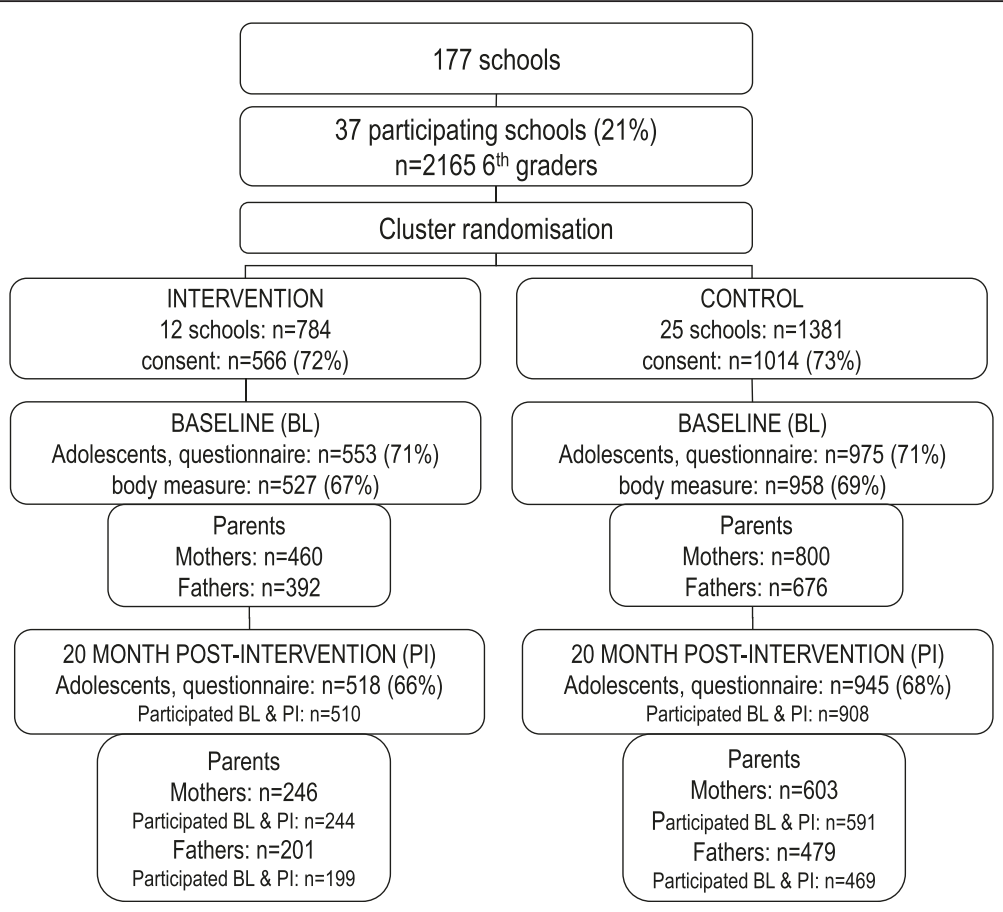

Figure 1 Flow diagram of recruitment, randomization, consent received and participants in the HEIA study. 
game-use. This sheet was meant to be delivered to the parents by the adolescents after the completion of the screen behaviour computer tailoring session.

\section{Measures and procedures}

The adolescents' self-reported age, gender, potential mediators (parental regulation of TV-viewing and computer/ game-use) and screen behaviours in an internet-based questionnaire which took about 45 min to complete, and participated in measurements of anthropometric parameters at baseline and post-intervention. Parental paper and pencil questionnaires were brought home to the parents by the adolescents and returned to the teachers in a sealed envelope which were collected from the school by project staff. Parental education was reported by the parents on the informed consent and categorized into 12 years or less, between 13 and 16 years and more than 16 years. The parent with the longest education was used for the adolescents' parental educational background, or else the one available.

\section{Adolescents' screen behaviours}

Four questions with pre-coded answer categories were asked to assess usual TV-viewing (including DVD) and use of computer/electronic games: How many hours do you usually watch TV and/or DVD on a normal weekday? The same question was asked for a normal weekend day. The answer categories were (recoding in parentheses): half hour (0.5), one hour (1), two hours (2), three hours (3), four hours (4), five hours or more (5). The two questions on computer/electronic game-use were formulated in the same way as for TV/DVD, but the answer categories were: no playing (0), half hour or less (0.5), one hour (1), two hours (2), three hours (3), four hours or more (4).

\section{Mediators}

The adolescents reported two mediators of screen behaviour both assessed by four items using a 5-point Likert scale (1 "totally disagree" to 5 "totally agree") based on Hardy et al. [37]: Perceived parental regulation of $T V$-viewing (e.g. "My mother and father try to make sure I do not watch too much TV"; Cronbach's alpha $(\alpha)$ at baseline/post-intervention of three items: 0.62/0.73) and Perceived parental regulation of computer/game-use (e.g. "My mother and father try to make sure that I do not use the computer and play games too much"; $\alpha$ at baseline/post-intervention of three items: $0.67 / 0.74$ ).

The mothers and fathers also reported two (corresponding) potential mediators of the adolescents' TV and computer/electronic game-use; Parental regulation of $T V$-viewing with six items using a 5-point Likert scale (e.g. "I permit my child to watch the TV programmes he/she wants to"; $\alpha$ at baseline/post-intervention of five items: $0.68 / 0.63$ reported by mothers, $0.69 / 0.69$ by fathers) and Parental regulation of computer/game-use with four items using a 5-point Likert scale (e.g. "I restrict how much time my child spend using the computer for playing games and so on"; $\alpha$ at baseline/postintervention: $0.76 / 0.75$ reported by mothers, $0.74 / 0.74$ by fathers), based on Hardy et al. [37]. Composite scores for each mediator variable were computed by summing the number of items divided by the numbers to keep the range across variables from 1.00-5.00.

A separate test-retest study was conducted prior to the main study; adolescents $(\mathrm{n}=114)$, mothers $(\mathrm{n}=44)$ and fathers $(n=35)$. The adolescents' screen behaviours and perceived parental regulation of TV-viewing and computer/game-use, and parents reports of regulation of TV-viewing and computer/game-use showed either moderate, good or excellent test-retest results (ICC $=$ 0.43-0.84).

\section{Anthropometrics}

Height and weight of the adolescents were measured by project staff [35]. The baseline values were used to categorize the adolescents as normal weight and overweight/obese using the body mass index cut-offs values proposed by the International Obesity Task Force [38].

\section{Statistical analyses}

Independent $\mathrm{t}$-tests and chi-square tests were conducted to test for differences between the intervention and control group in demographics, screen behaviours and mediators at baseline for adolescents and parents, and in the attrition analyses.

As school clustering effects explained only between $1.7-2.1 \%$ of the unexplained variance in the screen behaviours, all analyses were done without adjusting for the school clustering [39]. The product-of-coefficient test using linear regression was conducted to examine main and mediating effects [40] applying the script by Preacher \& Hayes [41]. This test consists of: 1) estimating the main effect of the intervention on the four screen behaviours (c-coefficient); 2) estimating the effect of the intervention on changes in the potential mediators (a-coefficient); 3) estimating the independent effect of changes in the potential mediators on change in the screen behaviours adjusted for the intervention condition (b-coefficient); and (4) computing the product of the two coefficients $(\mathrm{a} * \mathrm{~b})$, representing the mediated effect. All models were based on post-intervention variables adjusted for baseline values. The confidence interval of the mediated effect was calculated using bootstrapping with 1000 resamples of the data. Since mediating effects can still exist without a significant intervention effect on the outcome [42], mediation analyses were also conducted in its absence. 
Secondly, in separate analyses the moderating influences of gender and weight status on the main effects were studied by linear regression models including the relevant interaction terms (e.g. intervention"gender). When significant moderating influences were revealed, subgroup analyses based on the moderator (girls vs. boys) and/or weight status (normal vs. overweight) were carried out for the main and mediated effects, using the same product-of-coefficient test applying the script by Preacher and Hayes [41].

Thirdly, the moderating influences of gender and/or weight status on the mediating effects were studied (Figure 2) by conducting the separate mediation model method. In this method, the ab-coefficients for the groups (normal weight vs. overweight) are compared (e.g. a"b $b_{\text {normal weight }}-a^{*} b_{\text {overweight }}$ ) and if they were significantly different from each other, it indicates a significant moderation of the mediated effect. To test difference in ab-coefficients between the subgroups for statistical significance, the difference was divided by the pooled standard error (e.g. $s_{\text {pooled }}=\sqrt{ }\left(s_{\text {ab_normal weight }}^{2}+\right.$ $\mathrm{s}^{2}$ ab_overweight) [43].

To control for potential effects of covariates, all analyses on TV-viewing were adjusted for parental education level and weight status, and all analyses on computer/game-use were adjusted for parental education level, weight status and gender. Analyses were performed using IBM SPSS Statistics, version 18.0. The alpha level was set at $\mathrm{p}<.05$, except for the moderation test where $\mathrm{p}<.10$ was used $[33,44]$.

\section{Results}

Baseline characteristics

No significant baseline differences between the control and intervention group were found for the demographic variables or the screen behaviours (Tables 1 and 2).
The attrition analyses showed no differences between adolescents who participated twice $(\mathrm{n}=1418)$ and those participating at baseline only $(\mathrm{n}=110)$ for baseline values for the screen behaviours, the mediators (parental regulation), the gender distribution, age or parental education. However, a higher number of overweight adolescents were found among those participating at baseline only $(22.9 \%$ vs. $13.4 \%, \mathrm{p}=0.01)$. Among those lost to post-intervention, no differences between control and intervention group were found (data not shown).

In the subsample containing parents and adolescents (Table 3), TV-viewing weekday was significantly higher among those adolescents with mothers (1.5 vs. 1.4, $\mathrm{p}=.03)$ and fathers (1.5 vs. $1.4, \mathrm{p}=.007)$ participating at baseline only ( $\mathrm{n}$ mothers $=831$; $\mathrm{n}$ fathers $=746)$ vs. both time-points ( $\mathrm{n}$ mothers $=579, \mathrm{n}$ fathers $=664)$, and computer/game-use weekday was significantly higher among those adolescents with fathers $(1.2$ vs. $1.0, \mathrm{p}=0.02)$ participating at baseline only $(\mathrm{n}=744)$ vs. both time-points $(\mathrm{n}=665)$ (data not shown).

\section{Intervention effect on screen behaviours}

The results of the main effect analysis on the screen behaviours are shown in Table 2. There were no main effects seen in the total sample. However, weight status moderated the effect on weekdays TV-viewing $(\mathrm{p}=.04)$ and on computer/game-use $(\mathrm{p}=.08)$, and gender moderated the effect on weekend computer/game-use $(\mathrm{p}=.09)$. The following stratified analyses (Table 2 ) revealed an effect on weekday TV-viewing ( $\mathrm{c}=-0.12$; 95\% CI $(-0.24,-0.01) ; \mathrm{p}=.04)$.

Table 3 shows the baseline and post-intervention values of the investigated mediators. Mothers' and fathers' report of regulation of TV-viewing and fathers' report of regulation of computer/game-use were significantly higher in the intervention group, but baseline values were adjusted for in all analyses.

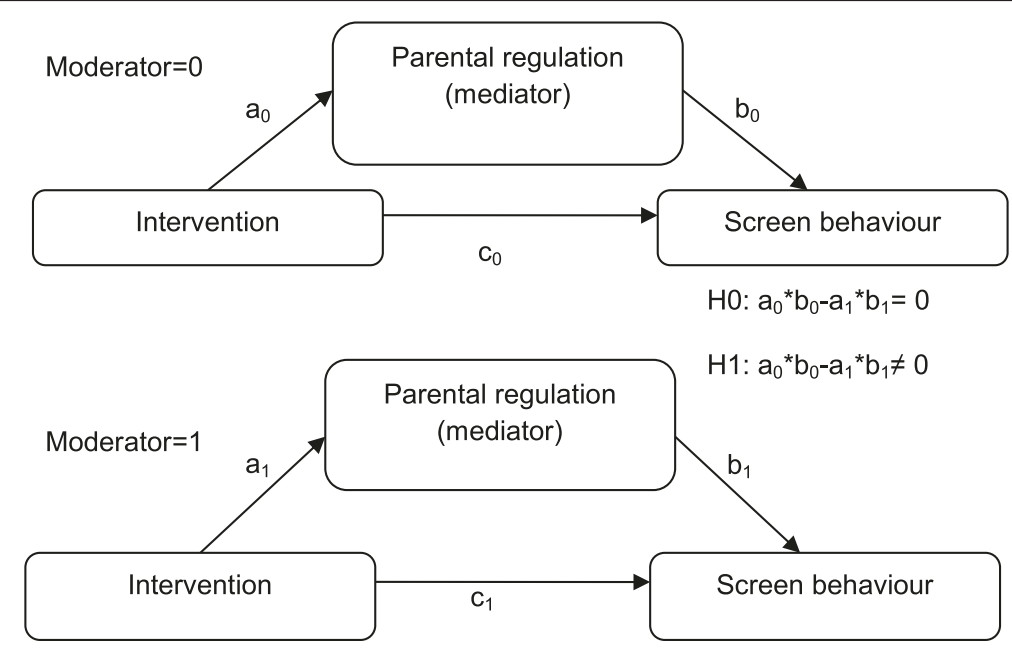

Figure 2 Conceptual model of moderation of a mediated effect. 
Table 1 Baseline characteristics for intervention and control group in the HEIA study

\begin{tabular}{|c|c|c|c|}
\hline & $\begin{array}{l}\text { Control } \\
(n=908)^{a}\end{array}$ & $\begin{array}{l}\text { Intervention } \\
(\mathrm{n}=510)^{\mathrm{a}}\end{array}$ & $\mathrm{p}$ \\
\hline Age (mean; SD) & $11.2(0.27)$ & $11.2(0.26)$ & .38 \\
\hline \multicolumn{4}{|l|}{ Gender } \\
\hline Girls (n; \%) & $434(47.8 \%)$ & $253(49.6 \%)$ & .55 \\
\hline \multicolumn{4}{|l|}{ Weight status } \\
\hline Overweight/obese $(n ; \%)^{b}$ & $130(14.5 \%)$ & $55(11.4 \%)$ & .12 \\
\hline \multicolumn{4}{|l|}{ Parental education } \\
\hline Low ( $\leq 12$ years) $(n ; \%)$ & $275(31.1 \%)$ & $129(26.2 \%)$ & .15 \\
\hline $13-16$ years $(n ; \%)$ & $317(35.8 \%)$ & $186(37.7 \%)$ & \\
\hline$>16$ years $(n ; \%)$ & $293(33.1 \%)$ & $178(36.1 \%)$ & \\
\hline
\end{tabular}

SD: standard deviation.

${ }^{a} \mathrm{n}$ varies somewhat for weight status and parental education level.

boverweight/obese is presented and treated as one group in the analyses due to the low proportion of obese $(C=1.6 \% ; \mathrm{l}=1.2 \%)$.

\section{Mediated effect}

Table 4 shows effect of the intervention on the mediators (parental regulation), the effect of the mediator on the screen behaviours, and the mediated effects of all hypothesized mediators of the intervention effect on the screen behaviours reported by the adolescents, and the mothers and the fathers respectively in the total sample. The intervention did not affect parental regulation (a-coefficients) neither when reported by the adolescents themselves or by any of the parents.

Changes in adolescents' perception of parental regulation of TV-viewing and computer/game-use were not associated with change in any of the corresponding screen behaviours. However, more regulation of TV-viewing by mothers' reports was associated with less weekday $\mathrm{TV}$-viewing $(b=-0.17 ; \quad(C I=-0.29,0.06), \quad p<.01)$ and weekend TVviewing $(b=-0.16 ;(C I=-0.30,-0.02) ; p<.05)$. Enhanced regulation of computer/game-use by both mothers' $(\mathrm{b}=$ $-0.17 ;(\mathrm{CI}=-0.27,-0.07) ; \mathrm{p}<.001)$ and fathers' $(\mathrm{b}=-0.14$; $(\mathrm{CI}=-0.24,-0.04) ; \mathrm{p}<.01)$ reports were associated with less weekday computer/game-use. None of the hypothesized mediators reported by the adolescents or the parents mediated the intervention effect on any of the behaviours.

\section{Moderation of gender on mediated effect on weekend computer/game-use}

The separate mediation models by gender for weekend computer/game-use (results not shown) did not reveal

Table 2 Descriptives for screen behaviours, main intervention effects in all and by weight status and gender

\begin{tabular}{|c|c|c|c|c|c|c|}
\hline & \multicolumn{2}{|c|}{ Baseline $^{a}$} & \multicolumn{2}{|c|}{ Post-intervention } & \multirow[b]{2}{*}{ Main intervention effect } & \multirow{3}{*}{$p$} \\
\hline & $\begin{array}{c}\text { Control } \\
(n=908)\end{array}$ & $\begin{array}{l}\text { Intervention } \\
(n=510)\end{array}$ & $\begin{array}{c}\text { Control } \\
(n=908)\end{array}$ & $\begin{array}{l}\text { Intervention } \\
(n=510)\end{array}$ & & \\
\hline & Mean (SD) & Mean (SD) & Mean (SD) & Mean (SD) & c-coeff $(95 \% \mathrm{Cl})$ & \\
\hline \multicolumn{7}{|c|}{ Weekday TV-viewing ${ }^{\text {b,d }}$} \\
\hline All & $1.45(0.99)$ & $1.47(1.08)$ & $1.70(1.06)$ & $1.63(1.15)$ & $-0.08(-0.19,0.04)$ & .18 \\
\hline Normal weight & $1.39(0.93)$ & $1.48(1.08)$ & $1.66(1.03)$ & $1.58(1.10)$ & $-0.12(-0.24,-0.01)$ & .04 \\
\hline Overweight & $1.82(1.21)$ & $1.64(1.15)$ & $1.90(1.16)$ & $2.07(1.39)$ & $0.22(-0.17,0.62)$ & .26 \\
\hline \multicolumn{7}{|c|}{ Weekend TV-viewing ${ }^{\mathrm{e}}$} \\
\hline All & $2.15(1.19)$ & $2.25(1.29)$ & $2.47(1.23)$ & $2.40(1.27)$ & $-0.12(-0.25,0.01)$ & .07 \\
\hline \multicolumn{7}{|c|}{ Weekday comp/game-use ${ }^{b, f}$} \\
\hline All & $1.13(0.92)$ & $1.07(0.92)$ & $1.37(1.04)$ & $1.32(1.02)$ & $-0.01(-0.12,0.11)$ & .93 \\
\hline Normal weight & $1.09(0.89)$ & $1.05(0.87)$ & $1.36(1.03)$ & $1.28(0.99)$ & $-0.04(-0.16,0.08)$ & .49 \\
\hline Overweight & $1.38(1.02)$ & $1.31(1.16)$ & $2.00(1.21)$ & $1.71(1.20)$ & $0.27(-.0 .10,0.62)$ & .15 \\
\hline \multicolumn{7}{|c|}{ Weekend comp/game-use ${ }^{b, g}$} \\
\hline All & $1.51(1.10)$ & $1.53(1.12)$ & $1.82(1.17)$ & $1.78(1.20)$ & $-0.06(-0.18,0.06)$ & .36 \\
\hline Girls & $1.24(1.00)$ & $1.20(0.95)$ & $1.68(1.12)$ & $1.51(1.09)$ & $-0.15(-0.32,0.03)$ & .09 \\
\hline Boys & 1.75 (1.14) & $1.84(1.19)$ & $1.94(1.19)$ & $2.05(1.24)$ & $0.02(-0.16,0.20)$ & .83 \\
\hline
\end{tabular}

c-coeff: c-coefficient; Comp/game: computer/game-use; SD: standard deviation.

TV-viewing and comp/game-use reported as hours/day.

a Baseline differences for screen behaviours were tested with independent t-test; no significant differences were found.

${ }^{b}$ Subgroup analyses based on preceding significant interaction analyses by gender or weight status.

Effect analyses for the whole sample for TV-viewing were adjusted for weight status and parental education level.

Effect analyses for the whole sample for computer/game-use were adjusted for gender, weight status and parental education level.

$n$ varies for the different behaviours:

$d_{n}$ in analyses for Weekday TV-viewing: All = 1299; normal weight $=1130$; overweight $=169$.

$e_{n}$ in analyses for Weekend TV-viewing: All $=1281$.

$f_{n}$ in analyses for Weekday comp/game-use: All =1286; normal weight $=1119$; overweight $=167$.

${ }^{g} \mathrm{n}$ in analyses for Weekend comp/game-use: All $=1272$; girls $=618$; boys $=654$. 
Table 3 Baseline and post-intervention descriptives of parental regulation of TV-viewing and computer/game-use

\begin{tabular}{|c|c|c|c|c|}
\hline & \multicolumn{2}{|c|}{ Baseline $^{a}$} & \multicolumn{2}{|c|}{ Post-intervention } \\
\hline & Control & Intervention & Control & Intervention \\
\hline & $\overline{\text { Mean (SD) }}$ & Mean (SD) & $\overline{\text { Mean (SD) }}$ & Mean (SD) \\
\hline \multicolumn{5}{|c|}{ Parental regulation TV-viewing, reported by ${ }^{b, c}$} \\
\hline Adolescents & $3.64(0.96)$ & $3.68(0.93)$ & $3.41(1.07)$ & $3.38(1.05)$ \\
\hline Mothers & $4.06(0.75)$ & $4.18(0.66)^{*}$ & $3.92(0.71)$ & $4.02(0.68)$ \\
\hline Fathers & $3.96(0.75)$ & $4.19(0.71)^{* * *}$ & $3.80(0.77)$ & $3.90(0.77)$ \\
\hline \multicolumn{5}{|c|}{ Parental regulation comp/game-use, reported by ${ }^{b, c}$} \\
\hline Adolescents & $3.55(0.99)$ & $3.53(1.01)$ & $3.28(1.11)$ & $3.28(1.10)$ \\
\hline Mothers & $4.13(0.84)$ & $4.20(0.70)$ & $3.98(0.80)$ & $3.97(0.80)$ \\
\hline Fathers & $3.99(0.82)$ & $4.14(0.72)^{*}$ & $3.77(0.83)$ & $3.87(0.79)$ \\
\hline
\end{tabular}

${ }^{*} \mathrm{p}<.05$, ${ }^{* * *} \mathrm{p}<.001$, otherwise non-significant.

Comp/game: computer/game-use; SD: standard deviation.

${ }^{a}$ Baseline differences between control and intervention for mediators were tested with independent t-test.

${ }^{\mathrm{b}}$ Range for regulation measures 1.00-5.00.

$c_{n}$ for parental regulation measures reported by: Adolescents 1390-1405; Mothers 764-775; Fathers 642-65.

any intervention effects on change in parental regulation indices among girls or boys neither when reported by the adolescents nor by their parents, and parental regulation of computer/game-use was not associated with change in computer/game-use on weekends. No mediation effect in girls or boys or moderation effects of gender on the mediated intervention effects were found.

\section{Moderation of weight status on mediated effect on} weekday TV and computer/game-use

Table 5 shows the separate mediation models by weight status for weekday TV-viewing and computer/game-use. There were no intervention effects on change in parental regulation indices among normal weight or overweight adolescents neither when reported by the adolescents nor their parents.

Among the normal weights, increase in parental regulation of TV-viewing by mothers' reports $(\mathrm{b}=-0.13,(\mathrm{CI}=$ $-0.26,-0.01) ; \mathrm{p}<.05)$ was associated with less weekday TV-viewing. Increase in regulation of computer/game-use by both mothers' $(\mathrm{b}=-0.15,(\mathrm{CI}=-0.26,-0.04) ; \mathrm{p}<.01)$ and fathers' $(b=-0.16 ;(C I=0.26,-0.06) ; \mathrm{p}<.01)$ reports was associated with less weekday computer/game-use.

Among the overweight adolescents, more regulation of TV-viewing by mothers' reports $(b=-0.39 ;(C I=-0.71$, $-0.06) ; \mathrm{p}<.05)$ was associated with less weekday TVviewing. No mediation effects were seen either among the normal weight or overweight adolescents. Still, weight

Table 4 Intervention effect on mediators, effect of mediators on four screen behaviours and mediated effect

\begin{tabular}{|c|c|c|c|c|c|c|}
\hline $\begin{array}{l}\text { Mediator: parental } \\
\text { regulation of TV-viewing } \\
\text { reported by }\end{array}$ & $\begin{array}{l}\text { Effect on } \\
\text { mediator } \\
\text { a }(95 \% \mathrm{Cl})\end{array}$ & $\begin{array}{l}\text { Effect of mediator } \\
\text { on weekday } \\
\text { TV viewing } \\
\text { b }(95 \% \mathrm{Cl})\end{array}$ & $\begin{array}{c}\text { Mediated } \\
\text { effect } \\
\text { ab }(95 \% \mathrm{Cl})\end{array}$ & $\begin{array}{l}\text { Effect on } \\
\text { mediator } \\
\text { a }(95 \% \mathrm{Cl})\end{array}$ & $\begin{array}{l}\text { Effect of mediator } \\
\text { on weekend } \\
\text { TV-viewing } \\
\text { b }(95 \% \mathrm{Cl})\end{array}$ & $\begin{array}{c}\text { Mediated effect } \\
\text { ab }(95 \% \mathrm{Cl})\end{array}$ \\
\hline Adolescents $^{a}$ & $-0.04(-0.15 ; 0.07)$ & $-0.04(-0.10 ; 0.01)$ & $0.00(0.00 ; 0.01)$ & $-0.03(-0.14 ; 0.09)$ & $-0.01(-0.13 ; 0.00)$ & $0.00(0.00 ; 0.06)$ \\
\hline Mothers $^{b}$ & $0.03(-0.07 ; 0.12)$ & $-0.17(-0.29 ;-0.06)^{* *}$ & $-0.01(-0.02 ; 0.01)$ & $0.02(-0.08 ; 0.12)$ & $-0.16(-0.30 ;-0.02)^{*}$ & $-0.00(-0.02 ; 0.01)$ \\
\hline Fathers ${ }^{c}$ & $-0.00(-0.12 ; 0.11)$ & $-0.04(-0.15 ; 0.07)$ & $-0.00(-0.01 ; 0.01)$ & $-0.02(-0.14: 0.09)$ & $-0.08(-0.30 ;-0.02)$ & $0.00(-0.01 ; 0.03)$ \\
\hline $\begin{array}{l}\text { Mediator: parental } \\
\text { regulation of } \\
\text { comp/game-use } \\
\text { reported by }\end{array}$ & $\begin{array}{l}\text { Effect on } \\
\text { mediator } \\
\text { a }(95 \% \mathrm{Cl})\end{array}$ & $\begin{array}{l}\text { Effect of mediator } \\
\text { on weekday } \\
\text { comp/game-use } \\
\text { b }(95 \% \mathrm{Cl})\end{array}$ & $\begin{array}{c}\text { Mediated } \\
\text { effect } \\
\text { ab }(95 \% \mathrm{Cl})\end{array}$ & $\begin{array}{l}\text { Effect on } \\
\text { mediator } \\
\text { a }(95 \% \mathrm{Cl})\end{array}$ & $\begin{array}{l}\text { Effect of mediator } \\
\text { on weekend } \\
\text { comp/game-use } \\
\text { b }(95 \% \mathrm{Cl})\end{array}$ & $\begin{array}{c}\text { Mediated effect } \\
\text { ab }(95 \% \mathrm{Cl})\end{array}$ \\
\hline Adolescents $^{a}$ & $0.03(-0.09 ; 0.15)$ & $-0.01(-0.06 ; 0.04)$ & $-0.00(-0.01 ; 0.00)$ & $0.03(-0.10 ; 0.15)$ & $-0.02(-0.07 ; 0.04)$ & $-0.00(-0.01 ; 0.00)$ \\
\hline Mothers $^{b}$ & $-0.04(-0.15 ; 0.08)$ & $-0.17(-0.27 ;-0.07)^{* * *}$ & $0.07(-0.01 ; 0.03)$ & $-0.03(-0.10 ; 0.15)$ & $-0.05(-0.16 ; 0.07)$ & $0.00(-0.00 ; 0.02)$ \\
\hline Fathers ${ }^{c}$ & $0.05(-0.08 ; 0.18)$ & $-0.14(-0.24 ;-0.04)^{* *}$ & $-0.01(-0.01 ; 0.03)$ & $0.05(-0.10 ; 0.15)$ & $-0.06(-0.16 ; 0.07)$ & $-0.00(-0.03 ; 0.00)$ \\
\hline
\end{tabular}

${ }^{*} \mathrm{p}<.05,{ }^{* *} \mathrm{p}<.01,{ }^{* * *} \mathrm{p}<.001$, otherwise non-significant.

Comp/game-use: computer/game-use; SD: standard deviation.

Analyses for TV-viewing were adjusted for weight status and parental education level.

Analyses for computer/game-use were adjusted for gender, weight status and parental education level.

${ }^{a} n$ in analyses for adolescents: Weekday TV viewing $=1299 ;$ Weekend TV viewing =1281; Weekday computer/game-use $=1286 ;$ Weekend computer/game-use $=1272$.

${ }^{b} \mathrm{n}$ in analyses for mothers: Weekday TV viewing $=708$; Weekend TV viewing $=698$; Weekday computer/game-use $=693$; Weekend computer/game-use $=687$.

$c_{n}$ in analyses for fathers: Weekday TV viewing $=601$; Weekend TV viewing = 591; Weekday computer/game-use = 599; Weekend computer/game-use $=592$. 
Table 5 Intervention effect on mediators, effect of mediators on outcomes, mediated effect and moderated mediation of weight status

\begin{tabular}{|c|c|c|c|c|c|c|c|}
\hline Mediators & & Normal weight & & & Overweight & & \\
\hline $\begin{array}{l}\text { Parental regulation } \\
\text { of TV-viewing, } \\
\text { reported by }\end{array}$ & $\begin{array}{l}\text { Intervention effect } \\
\text { on mediator } \\
\text { a }(95 \% \mathrm{Cl})\end{array}$ & $\begin{array}{c}\text { Effect of mediator } \\
\text { on weekday TV-viewing } \\
\text { b }(95 \% \mathrm{Cl})\end{array}$ & $\begin{array}{c}\text { Mediated effect } \\
\text { ab }(95 \% \mathrm{Cl})\end{array}$ & $\begin{array}{l}\text { Intervention effect } \\
\text { on mediator } \\
\text { a ( }(95 \% \mathrm{Cl})\end{array}$ & $\begin{array}{l}\text { Effect of mediator on } \\
\text { weekday TV-viewing } \\
\text { b }(95 \% \mathrm{Cl})\end{array}$ & $\begin{array}{c}\text { Mediated effect } \\
\text { ab }(95 \% \mathrm{Cl})\end{array}$ & $\begin{array}{c}\text { Moderated } \\
\text { mediation } \\
\Delta \mathrm{ab}(95 \% \mathrm{Cl})\end{array}$ \\
\hline Adolescents & $-0.05(-0.18 ; 0.08)$ & $-0.04(-0.10 ; 0.02)$ & $-0.02(-0.00 ; 0.01)$ & $0.00(-0.34 ; 0.35)$ & $-0.07(-0.24 ; 0.10)$ & $-0.00(-0.06 ; 0.04)$ & $0.01(-0.01 ; 0.03)$ \\
\hline Mothers & $0.01(-0.09 ; 0.10)$ & $-0.13(-0.26 ;-0.01)^{*}$ & $-0.00(-0.02 ; 0.01)$ & $0.22(-0.13 ; 0.57)$ & $-0.39(-0.71 ;-0.06)^{*}$ & $-0.09(-0.33 ; 0.01)$ & $0.09(0.08 ; 0.10)^{* *}$ \\
\hline Fathers & $-0.00(-0.12 ; 0.12)$ & $-0.07(-0.18 ; 0.04)$ & $-0.00(-0.01 ; 0.02)$ & $0.08(-0.26 ; 0.42)$ & $0.42(-0.09 ; 0.93)$ & $0.03(-0.13 ; 0.29)$ & $-003(-0.09 ; 0.03)$ \\
\hline $\begin{array}{l}\text { Parental regulation } \\
\text { of comp/game-use, } \\
\text { reported by }\end{array}$ & $\begin{array}{l}\text { Intervention effect } \\
\text { on mediator } \\
\text { a }(95 \% \mathrm{Cl})\end{array}$ & $\begin{array}{c}\text { Effect of mediator } \\
\text { on weekday comp/game-use } \\
\text { b }(95 \% \mathrm{Cl})\end{array}$ & $\begin{array}{l}\text { Mediated effect } \\
\text { ab }(95 \% \mathrm{Cl})\end{array}$ & $\begin{array}{l}\text { Intervention effecton } \\
\text { mediator } \\
\text { a }(95 \% \mathrm{Cl})\end{array}$ & $\begin{array}{c}\text { Effect of mediator } \\
\text { weekday comp/game-use } \\
\text { b }(95 \% \mathrm{Cl})\end{array}$ & $\begin{array}{l}\text { Mediated effect } \\
\text { ab }(95 \% \mathrm{Cl})\end{array}$ & $\begin{array}{c}\text { Moderated } \\
\text { mediation } \\
\Delta \mathrm{ab}(95 \% \mathrm{Cl})\end{array}$ \\
\hline Adolescents & $0.05(-0.08 ; 0.18)$ & $-0.01(-0.06 ; 0.05)$ & $-0.00(-0.01 ; 0.00)$ & $-0.11(-0.47 ; 0.24)$ & $-0.04(-0.19 ; 0.12)$ & $0.01(-0.01 ; 0.06)$ & $-0.01(-0.03 ; 0.05)$ \\
\hline Mothers & $-0.05(-0.17 ; 0.07)$ & $-0.15(-0.26 ;-0.04)^{* *}$ & $0.01(-0.01 ; 0.04)$ & $0.05(-0.36 ; 0.47)$ & $-0.28(-0.55 ;-0.01)^{\#}$ & $-0.02(-0.16 ; 0.09)$ & $0.03(-0.07 ; 0.01)$ \\
\hline Fathers & $0.06(-0.07 ; 0.20)$ & $-0.16(-0.26 ;-0.06)^{* *}$ & $-0.01(-0.04 ; 0.01)$ & $-0.05(-0.45 ; 0.36)$ & $0.04(-0.37 ; 0.45)$ & $-0.00(-0.14 ; 0.11)$ & $-0.01(-0.05 ; 0.03)$ \\
\hline
\end{tabular}

${ }^{\#} \mathrm{p}<.10,{ }^{*} \mathrm{p}<.05,{ }^{* *} \mathrm{p}<.01$, otherwise non-significant.

Comp/game-use: computer/game-use; SD: standard deviation

Stratified analyses on TV-viewing were adjusted for parental education level.

Stratified analyses on computer/game-use were adjusted for gender and parental education level.

$a_{n}$ in analyses for Weekday TV-viewing: Adolescents: normal weight weight $=1130$, overweight $=169$; Mothers: normal weight $=620$, overweight $=88$; Fathers: normal weight $=538$, overweight $=63$.

$b_{n}$ in analyses for Weekday comp/game-use: Adolescents: normal weight $=1119$, overweight $=167$; Mothers: normal weight $=607$, overweight $=86$; Fathers: normal weight $=535$, overweight $=64$. 
status did moderate the mediating effect of mother's regulation of weekday TV-viewing, indicating that mother's regulation of TV-viewing in the intervention did differ between normal weight and overweight adolescents.

\section{Discussion}

\section{Main and moderated effects on the screen behaviours}

There was no main effect on any of the screen behaviours in the whole sample, but moderation effects of gender and weight status were revealed. The stratified follow-up analyses showed a significant effect among the normal weight (comprising $84 \%$ of the sample) on weekday TV-viewing. TV-viewing has been forwarded as the most important screen behaviour when it comes to prevention of overweight probably due to TV-viewings' association with caloric intake (snacking) [45]. Nevertheless, the mid-way assessment (at 8 months) showed effect on both TV-viewing and computer/game-use, but in girls only [34]. In addition, the magnitude of the effect on daily weekday TV-viewing in this study (about $7 \mathrm{~min} /$ day) is less than the largest effect observed at the mid-way assessment (about $18 \mathrm{~min} /$ day) [34]. However, a reduction in effect as the intervention moves along is in line with the review by Kamath et al. [15] showing larger in-treatment effects than post-treatment effects of intervention targeting screen behaviours. Still, small effects for behaviours that are common in a large part of a population, as is the case for TV-viewing among youth, may be important at the population level [16].

The effect on TV-viewing may also have contributed to the favourable post-intervention effects observed in the HEIA-study for total sedentary time (22 min in girls) [46]. In addition, reduced TV-viewing among the normal weight could reflect that they have substituted parts of watching TV with physical activity. Indeed, a postintervention effect on overall physical activity among the normal weight has been observed [46]. These effects taken together could contribute to a change in the energy-balance that might be of importance in obesity prevention. Also, a small effect on BMI has been observed among girls in the HEIA study [47]. However, both this study and the other findings from the HEIAproject, support previous research showing that energybalance related behaviour interventions may not reach all equally well, and that the effect may vary by gender and weight status $[4,33]$.

In addition, the intervention effect on weekday TVviewing among the normal weight, together with the tendency (non-significant) for an effect in the undesired direction among the overweight (Table 2) may explain the apparent non-effect in the total sample. This is in line with the supposition by Kamath et al. [15] that variation in results could stem from studies with both normal weight and overweight compared to intervention with only normal weight. It is also discussed that prevention of excessive weight in those who are not yet overweight may be more effective than targeting mixed groups [48]. However, we can only speculate why the overweight did not respond to the intervention as intended. It might be that they lack alternatives to screen entertainment, or respond with a sort of reactance (by becoming more sedentary) when confronted with initiatives to reduce TV-viewing [49]. Indeed, unexpected results among the overweight group have also been seen previously in the HEIA-study. An unbeneficial effect on enjoyment of physical activity among the overweight has been reported [36]. At the same time there was no effect on accelerometer assessed physical activity among the overweight, but rather a tendency for an unfavourable effect in this group [46].

\section{Mediating effects and moderated mediating effects}

In line with previous mediating studies of screen behaviours change, lack of mediated effects, were mainly due to the lack of intervention effect on the potential mediators [24]. Ineffective strategies or too low intervention dosage received may explain this. To provide parents with written material to the home may not be an effective strategy to reach parents [32]. In addition, the dose of the fact sheets might not have been powerful enough to create an impact on the potential mediators. Process evaluation also suggest that a relatively low proportion of the participating parents received all the fact sheets [50], and not all parents did respond to the parental questionnaire (Figure 1) which may indicate low parental involvement. In addition, the relatively high baseline values of the parental regulation constructs (mean: 3.534.20 , Table 3 ) both by adolescents' and parents' reports may have led to ceiling effects, and it may also be that the measures were not sensitive enough to detect change. No mediation effect on screen behaviours have been identified by other previously examined potential mediators either [51-53].

Although parental regulation was not affected by the intervention, changes in parental regulation of both TVviewing and computer/game-use were associated with changes in the respective behaviours in the expected direction (b-coefficient analyses, Tables 4 and 5) with some differences among the subgroups. This is an important finding, providing prospective evidence for increase in parental regulation predicting reduction in screen behaviours.

Interestingly, mothers' reports of regulation of screen behaviours were more often associated with reduction in the screen behaviours than fathers' reports, which may mean that mothers are more involved in trying to regulate the adolescents' TV-viewing and computer/gameuse. However, both parents' reports of regulation were 
more often found to be associated with change in the screen behaviours than adolescents' perceived regulation of these behaviours. This difference may be due to young adolescents having difficulties recalling accurately or and/or parents being prone to a social desirability response bias. Another reason could be that parents and adolescents differ in their perception about parental practices. In addition, the wording of the regulation measures was a bit more specifically phrased to the parents compared to the adolescents, which could have influenced the results. However, it seems important to assess, include and describe reports by both parents (mothers and fathers) and children/adolescents, when assessing parental regulation of screen behaviours. In addition, both mothers and fathers should be encouraged to regulate their adolescents screen behaviours. Change in parental regulation was primarily found to be associated with change in weekday screen behaviours (except for mothers' reports of regulation of weekend TV-viewing) which is in line with recent cross-sectional findings for restriction on sedentary behaviour [54]. Hence, interventions need to stimulate parents to regulate $\mathrm{TV}$-viewing and computer/game-use on weekends also.

The intervention did not affect mother's regulation of TV-viewing either among the normal weight or overweight adolescents, and no complete mediation effects were seen on change in weekday TV-viewing in either group. Still, we found a moderated mediating effect of weight status on mothers' parental regulation on weekday TV-viewing (Table 5, $\Delta$ ab-coefficient). This result indicates that the mediating mechanisms of mothers' parental regulation of TV-viewing weekday differed between normal weight and overweight adolescents. Stronger influence of mother's regulation on TV-viewing among the overweight (Table 5, b-coefficient) may partly explain the result, which may also indicate that mothers' parental regulation is a more influential determinant among overweight adolescents.

\section{Strength and limitations}

This was a randomized controlled, long term intervention study including a relative large sample size with high retention rate for the adolescents. To our knowledge this is the first intervention study to investigate whether change in parental regulation, using both parents' and adolescents' reports, mediated young adolescents' screen behaviours. Furthermore, main and mediated effects on both TV-viewing and computer/game-use were investigated, in addition to moderating effect of gender and weight status on the main effects on the screen behaviours and on the mediation mechanisms. Few studies have up to now included data from both mother and fathers, but this study explored mediation of parental regulation reported by both parents.
Both the internal consistency and the test-retest results (ICC) of the parental regulation measures were acceptable. However, the measures were phrased in a general format and did not differentiate between regulation on weekday and weekend as the report of screen behaviours did. A more context specific phrasing of the investigated mediators could possibly have improved their sensitivity to measure change. No differences for the screen behaviours were seen between those adolescents providing data at both time points and those lost to postintervention. However, not all parents of participating adolescents did answer the parental survey, and the attrition analyses for the adolescents with parental data show that parents who did provide data at both time points were parents of adolescents having slightly more favourable screen behaviours than those adolescents with parents who were lost to post-intervention. So the parents included and retained in the study may be a biased subsample. Other limitations include the single items used to measure TV-viewing and computer/gameuse, which gives only crude estimates [55]. However, the test-retest results (ICC) for these outcomes were moderate to high. While social desirability may have led to an under-reporting of the screen behaviours and a possible over-reporting of the potential mediators, descriptive results do not support this supposition given higher postintervention values for the screen behaviours and lower post-intervention values of the mediators in both conditions (Tables 2 and 3). However, adolescents lost to postintervention assessment were more likely to be overweight, which may indicate that the proportion of overweight may be somewhat lower in this sample than the population it represents. All the same, there were no differences between the control and intervention group among those lost to post-intervention or in the analysed sample.

\section{Conclusion}

Taken together results revealed that this multiple behaviour intervention did not affect all equally well, by showing moderating effects by weight status and gender. Further studies should continue to investigate for whom interventions are effective or not. Parental regulation did not mediate screen behaviour effects and more intense targeting of this potential mediator may be needed probably combined with other strategies. Nevertheless, mothers' and fathers' reports of regulation of TV-viewing and computer/game-use seem to be social-environmental determinants of both TV-viewing and computer/gameuse. Thus, parental regulation is warranted to target in future interventions, and both fathers and mothers should be encouraged to regulate their adolescents' screen behaviours on both weekdays and weekends. However, more studies investigating mediation effect of screen behaviours are warranted. 


\section{Additional file}

\section{Additional file 1: Assessment of screen behavior time in the} computer tailoring program.

\section{Competing interests}

The authors declare that they have no competing interests.

\section{Authors' contributions}

IHB conducted the statistical analyses assisted by MM van S, wrote the first draft of the manuscript and made the greatest contribution to the paper. MB, MG, NL, K-IK, SAA and YO participated in designing the study, project planning and data collection. All authors have critically revised the manuscript, and read and approved the final version of the manuscript.

\section{Acknowledgements}

All the participants and the project staff are gratefully acknowledged. The HEalth In Adolescents study was supported by the Norwegian Research Council (grant number 175323N50) with supplementary funds from the Throne Holst Nutrition Research Foundation, University of Oslo and the Norwegian School of Sport Sciences. The paper was prepared in cooperation with the ENERGY project. The ENERGY project is funded by the Seventh Framework Programme (CORDIS FP7) of the European Commission, HEALTH (FP7-HEALTH-2007-B) grant number 223254. The content of this article reflects only the authors' views and the European commission is not liable for any use that may be made of the information contained therein. In addition, part of the work on the paper was financially supported by the Netherlands Organization for Health Research and Development (grant number ZonMw 121.520.002) and the World Cancer Research Fund (grant number 2008/65).

\section{Author details}

${ }^{1}$ Department of Coaching and Psychology, Norwegian School of Sport Sciences, PB 4014 Ullevaal Stadion, Oslo NO-0886, Norway. ${ }^{2}$ EMGO Institute for Health and Care Research and Department of Public and Occupational Health, VU University Medical Center, Amsterdam 1081 BT, the Netherlands. ${ }^{3}$ Department of Nutrition, Faculty of Medicine, University of Oslo, Oslo NO-0316, Norway. ${ }^{4}$ Department of Sport Medicine, Norwegian School of Sport Sciences, PB 4014 Ullevaal Stadion, Oslo NO-0886, Norway. ${ }^{5}$ Department of Health Sciences and the EMGO Institute for Health and Care Research, Faculty of Earth and Life Sciences, VU University Amsterdam, de Boelelaan 1085, 1081, HV Amsterdam, the Netherlands.

Received: 4 February 2014 Accepted: 13 February 2014 Published: 25 February 2014

\section{References}

1. Lobstein $T$, Baur L, Uauy R: Obesity in children and young people: a crisis in public health. Obes Rev 2004, 5(Suppl 1):4-104.

2. Han JC, Lawlor DA, Kimm SY: Childhood obesity. Lancet 2010, 375:1737-1748.

3. Brug J, Van Stralen MM, Te Velde SJ, Chinapaw MJ, De BI, Lien N, Bere E, Maskini V, Singh AS, Maes L, Moreno L, Jan N, Kovacs E, Lobstein T, Manios $Y$ : Differences in Weight Status and Energy-Balance Related Behaviors among Schoolchildren across Europe: The ENERGY-Project. PLoS One 2012, 7:e34742.

4. Brown T, Summerbell C: Systematic review of school-based interventions that focus on changing dietary intake and physical activity levels to prevent childhood obesity: an update to the obesity guidance produced by the National Institute for Health and Clinical Excellence. Obes Rev 2009, 10:110-141.

5. van Grieken A, Ezendam NP, Paulis WD, van der Wouden JC, Raat H: Primary prevention of overweight in children and adolescents: a metaanalysis of the effectiveness of interventions aiming to decrease sedentary behaviour. Int J Behav Nutr Phys Act 2012, 9:61.

6. Altenburg TM, Singh AS, Van MW, Brug J, Chinapaw MJ: Direction of the association between body fatness and self-reported screen time in Dutch adolescents. Int J Behav Nutr Phys Act 2012, 9:4.

7. Ekelund U, Brage S, Froberg K, Harro M, Anderssen SA, Sardinha LB, Riddoch C, Andersen LB: TV viewing and physical activity are independently associated with metabolic risk in children: the European Youth Heart Study. PLoS Med 2006, 3:e488.

8. Chinapaw MJ, Proper Kl, Brug J, Van MW, Singh AS: Relationship between young peoples' sedentary behaviour and biomedical health indicators: a systematic review of prospective studies. Obes Rev 2011, 12:e621-e632.

9. Salmon J, Tremblay MS, Marshall SJ, Hume C: Health Risks, Correlates, and Interventions to Reduce Sedentary Behavior in Young People. Am J Prev Med 2011, 41:197-206.

10. Yang F, Helgason AR, Sigfusdottir ID, Kristjansson AL: Electronic screen use and mental well-being of 10-12-year-old children. Eur J Public Health 2013, 23:492-498.

11. Gorely T, Marshall SJ, Biddle SJH, Cameron N: The prevalence of leisure time sedentary behaviour and physical activity in adolescent girls: An ecological momentary assessment approach. Int J Pediatr Obes 2007, 2:227-234.

12. Gorely T, Biddle SJH, Marshall SJ, Cameron N: The prevalence of leisure time sedentary behaviour and physical activity in adolescent boys: An ecological momentary assessment approach. Int J Pediatr Obes 2009, 4:289-298.

13. Raudsepp L, Neissaar I, Kull M: Longitudinal stability of sedentary behaviors and physical activity during early adolescence. Pediatr Exerc Sci 2008, 20:251-262.

14. Biddle SJ, Pearson N, Ross GM, Braithwaite R: Tracking of sedentary behaviours of young people: a systematic review. Prev Med 2010, 51:345-351.

15. Kamath CC, Vickers KS, Ehrlich A, McGovern L, Johnson J, Singhal V, Paulo R, Hettinger A, Enwin PJ, Montori VM: Clinical review: behavioral interventions to prevent childhood obesity: a systematic review and metaanalyses of randomized trials. J Clin Endocrinol Metab 2008, 93:4606-4615.

16. Biddle SJ, O'Connell S, Braithwaite RE: Sedentary behaviour interventions in young people: a meta-analysis. Br J Sports Med 2011, 45:937-942.

17. Maniccia DM, Davison KK, Marshall SJ, Manganello JA, Dennison BA: A meta-analysis of interventions that target children's screen time for reduction. Pediatrics 2011, 128:e193-e210.

18. Gentile DA, Welk G, Eisenmann JC, Reimer RA, Walsh DA, Russell DW, Callahan R, Walsh M, Strickland S, Fritz K: Evaluation of a multiple ecological level child obesity prevention program: Switch (R) what you Do, View, and Chew. BMC Med 2009, 7:49.

19. Salmon J, Ball K, Hume C, Booth M, Crawford D: Outcomes of a grouprandomized trial to prevent excess weight gain, reduce screen behaviours and promote physical activity in 10-year-old children: Switch-Play. Int J Obes 2008, 32:601-612.

20. Singh AS, Chin APM, Brug J, Van MW: Dutch obesity intervention in teenagers: effectiveness of a school-based program on body composition and behavior. Arch Pediatr Adolesc Med 2009, 163:309-317.

21. Salmon J, Jorna M, Hume C, Arundell L, Chahine N, Tienstra M, Crawford D: A translational research intervention to reduce screen behaviours and promote physical activity among children: Switch-2-Activity. Health Promot Int 2011, 26:311-321.

22. Bauman AE, Sallis JF, Dzewaltowski DA, Owen N: Toward a better understanding of the influences on physical activity - The role of determinants, correlates, causal variables, mediators, moderators, and confounders. Am J Prev Med 2002, 23:5-14.

23. Baranowski T, Jago R: Understanding the mechanisms of change in children's physical activity programs. Exerc Sport Sci Rev 2005, 33:163-168.

24. Van Stralen MM, Yildirim M, te Velde SJ, Brug J, Van Mechelen W, Chinapaw MJ: What works in school-based energy balance behaviour interventions and what does not? A systematic review of mediating mechanisms. Int J Obes 2011, 35:1251-1265.

25. Pate RR, Mitchell JA, Byun W, Dowda M: Sedentary behaviour in youth. $\mathrm{Br}$ J Sports Med 2011, 45:906-913.

26. Ramirez ER, Norman GJ, Rosenberg DE, Kerr J, Saelens BE, Durant N, Sallis JF: Adolescent screen time and rules to limit screen time in the home. J Adolesc Health 2011, 48:379-385.

27. Hoyos Cl, Jago R: Systematic review of correlates of screen-viewing among young children. Prev Med 2010, 51:3-10.

28. Granich J, Rosenberg M, Knuiman M, Timperio A: Understanding children's sedentary behaviour: a qualitative study of the family home environment. Health Educ Res 2010, 25:199-210.

29. Carlson SA, Fulton JE, Lee SM, Foley JT, Heitzler C, Huhman M: Influence of limit-setting and participation in physical activity on youth screen time. Pediatrics 2010, 126:e89-e96. 
30. Verloigne M, Lippevelde $W$, Maes L, Yildirim M, ChinAPaw M, Manios $Y$, Androutsos O, Kovacs E, Bringolf-Isler B, Brug J, De Bourdeaudhuij I: Self-reported TV and computer time do not represent accelerometerderived total sedentary time in 10 to 12-year-olds. Eur J Public Health 2012, 23:30-32.

31. Uijtdewilligen L, Nauta J, Singh AS, Van MW, Twisk JW, van der Horst K, Chinapaw MJ: Determinants of physical activity and sedentary behaviour in young people: a review and quality synthesis of prospective studies. Br J Sports Med 2011, 45:896-905.

32. O'Connor TM, Jago R, Baranowski T: Engaging parents to increase youth physical activity a systematic review. Am J Prev Med 2009, 37:141-149.

33. Yildirim M, Van Stralen MM, Chinapaw MJBJ, Van Mechelen W, Twisk J, te Velde S: For Whom and Under What Circumstances Do School-based Interventions Aimed at Energy Balance Behaviour Work? Systematic Review on Moderators. Int J Pediatr Obes 2011, 6:e446-e457.

34. Bjelland M, Bergh $\mathrm{H}$, Grydeland M, Klepp Kl, Andersen LF, Anderssen SA, Ommundsen $\mathrm{Y}$, Lien $\mathrm{N}$ : Changes in adolescents' intake of sugarsweetened beverages and sedentary behaviour: Results at 8 month midway assessment of the HEIA study - a comprehensive, multi-component school-based randomized trial. Int J Behav Nutr Phys Act 2011, 8:63.

35. Lien $N$, Bjelland $M$, Bergh $H$, Grydeland $M$, Anderssen SA, Ommundsen $Y$, Andersen LF, Henriksen HB, Randby JS, Klepp Kl: Design of a 20-month comprehensive, multicomponent school-based randomised trial to promote healthy weight development among 11-13 year olds: The HEalth In Adolescents study. Scand J Public Health 2010, 38:38-51.

36. Bergh $I H$, Bjelland M, Grydeland M, Lien N, Andersen LF, Klepp K-I, Anderssen SA, Ommundsen Y: Mid-way and post-intervention effects on potential determinants of physical activity and sedentary, results of the HEIA study a multicomponent school-based randomized trial. Int J Behav Nutr Phys Act 2012, 9:63.

37. Hardy LL, Baur LA, Garnett SP, Crawford D, Campbell KJ, Shrewsbury VA, Cowell CT, Salmon J: Family and home correlates of television viewing in 12-13 year old adolescents: the Nepean Study. Int J Behav Nutr Phys Act 2006, 3:24.

38. Cole TJ, Bellizzi MC, Flegal KM, Dietz WH: Establishing a standard definition for child overweight and obesity worldwide: international survey. $\mathrm{Br}$ Med J 2000, 320:1240-1243.

39. Heck HR, Thomas SL, Tabata LN: Introduction to Multilevel and Longitudianl Modeling with IBM SPSS. In Multilevel and Longitudinal Modeling with IBM SPSS. 1st edition. New York: Routledge, Taylor and Francis group, LLC; 2010:1-20.

40. Mackinnon DP, Fairchild AJ, Fritz MS: Mediation analysis. Annu Rev Psychol 2007, 58:593-614

41. Preacher KJ, Hayes AF: Asymptotic and resampling strategies for assessing and comparing indirect effects in multiple mediator models. Behav Res Methods 2008, 40:879-891.

42. Cerin E, Mackinnon DP: A commentary on current practice in mediating variable analyses in behavioural nutrition and physical activity. Public Health Nutr 2009, 12:1182-1188.

43. Fairchild AJ, Mackinnon DP: A general model for testing mediation and moderation effects. Prev Sci 2009, 10:87-99.

44. Stone-Romero EF, Liakhovitski D: Strategies for detecting moderator variables: A review of conceptual and empirical issues. Res Pers Hum Resour Manage 2002, 21:333-372.

45. Rey-Lopez JP, Vicente-Rodriguez G, Biosca M, Moreno LA: Sedentary behaviour and obesity development in children and adolescents. Nutr Metab Cardiovasc Dis 2008, 18:242-251.

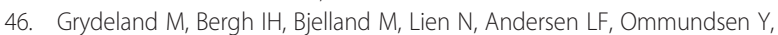
Klepp Kl, Anderssen SA: Intervention effects on physical activity: the HEIA study - a cluster randomized controlled trial. Int J Behav Nutr Phys Act 2013, 10:17.

47. Grydeland M, Bjelland M, Anderssen SA, Klepp K-I, Bergh $\amalg$, Andersen LF, Ommundsen $Y$, Lien N: Effects on anthropometric outcomes from a 20-month cluster randomized controlled school-based intervention: the HEIA study. Br J Sports Med. in press.

48. Simon C, Schweitzer B, Oujaa M, Wagner A, Arveiler D, Triby E, Copin N, Blanc S, Platat C: Successful overweight prevention in adolescents by increasing physical activity: a 4-year randomized controlled intervention. Int J Obes (Lond) 2008, 32:1489-1498.

49. Brehm JW: A Theory of Psychological Reactance. New York: Academic Press; 1966.
50. Bjelland M: Obesity prevention targeting Norwegian adolescents: prevalence rates, determinants and intervention effects by gender, parental education and parent-child associations. University of Oslo, Unipub: PhD thesis; 2011.

51. Robinson TN, Borzekowski DLG: Effects of the SMART classroom curriculum to reduce child and family screen time. J Commun 2006, $56: 1-26$.

52. Spruijt-Metz D, Nguyen-Michel ST, Goran MI, Chou CP, Huang TT: Reducing sedentary behavior in minority girls via a theory-based, tailored classroom media intervention. Int J Pediatr Obes 2008, 3:240-248.

53. Chin APM, Singh AS, Brug J, Van MW: Why did soft drink consumption decrease but screen time not? Mediating mechanisms in a school-based obesity prevention program. Int J Behav Nutr Phys Act 2008, 5:41.

54. Mcminn AM, Griffin SJ, Jones AP, van Sluijs EM: Family and home influences on children's after-school and weekend physical activity. Eur J Public Health 2012.

55. Bryant MJ, Lucove JC, Evenson KR, Marshall S: Measurement of television viewing in children and adolescents: a systematic review. Obes Rev 2007, 8:197-209.

doi:10.1186/1471-2458-14-200

Cite this article as: Bergh et al:: Post-intervention effects on screen behaviours and mediating effect of parental regulation: the HEalth In Adolescents study - a multi-component school-based randomized controlled trial. BMC Public Health 2014 14:200.

\section{Submit your next manuscript to BioMed Central and take full advantage of:}

- Convenient online submission

- Thorough peer review

- No space constraints or color figure charges

- Immediate publication on acceptance

- Inclusion in PubMed, CAS, Scopus and Google Scholar

- Research which is freely available for redistribution 